\title{
Principles and Prospects of Prunus Cultivation in Greenhouse
}

\author{
Pedro Martínez-Gómez ${ }^{1, *(1)}$, Sama Rahimi Devin ${ }^{2}$, Juan A. Salazar ${ }^{1}$, Jesús López-Alcolea ${ }^{1}$, Manuel Rubio ${ }^{1}$ (D) \\ and Pedro J. Martínez-García ${ }^{1}$ (D) \\ 1 Department of Plant Breeding, CEBAS-CSIC, P.O. Box 164, Espinardo, 30100 Murcia, Spain; \\ jasalazar@cebas.csic.es (J.A.S.); cebasfruit@cebasfruit.com (J.L.-A.); mrubio@cebas.csic.es (M.R.); \\ pjmartinez@cebas.csic.es (P.J.M.-G.) \\ 2 Department of Horticultural Science, College of Agriculture, Shiraz University, Shiraz 7144165186, Iran; \\ sama_rahimi@yahoo.com \\ * Correspondence: pmartinez@cebas.csic.es; Tel.: +34-968-396-200
}

Citation: Martínez-Gómez, P.; Rahimi Devin, S.; Salazar, J.A.;

López-Alcolea, J.; Rubio, M.;

Martínez-García, P.J. Principles and Prospects of Prunus Cultivation in Greenhouse. Agronomy 2021, 11, 474. https://doi.org/10.3390/ agronomy11030474

Academic Editor: Arnd Jürgen Kuhn

Received: 5 February 2021

Accepted: 27 February 2021

Published: 4 March 2021

Publisher's Note: MDPI stays neutral with regard to jurisdictional claims in published maps and institutional affiliations.

Copyright: (c) 2021 by the authors. Licensee MDPI, Basel, Switzerland. This article is an open access article distributed under the terms and conditions of the Creative Commons Attribution (CC BY) license (https:// creativecommons.org/licenses/by/ $4.0 /)$.

\begin{abstract}
Throughout history, new strategies and technologies have played a key role in promoting the development of agriculture. New strategies have led to substantial improvements in crop productivity and fruit quality. The cultivation of peach and apricot in controlled greenhouse conditions is one such strategy. The aim of the protected cultivation of these species in greenhouses is to grow fruit trees by modifying the natural environment of the tree, including the harvest duration, which can be extended. This protected cultivation should improve yield, thus increasing the benefit-cost ratio, especially in the case of organic production. Here we review the main factors involved in greenhouse fruit tree cultivation, including the planting systems and substrate, cultivar and rootstock selection, pollination management, orchard management, and environmental management. Greenhouse cultivation makes it possible to control environmental conditions like wind speed, moisture, temperature, mineral nutrients, light intensity, and the atmospheric composition, and thus gives us a better understanding of growth factor requirements, and the means to improve fruit productivity. A protected environment has been shown to be effective in maintaining a relatively high temperature and preventing leaf injury due to environmental factors, resulting in a longer period of photosynthetic activity, which increases the photosynthetic production, and is therefore a suitable alternative strategy for production in cold regions. The main benefits of apricot and peach cultivation in greenhouses are: (1) precocity; (2) high fruit quality, storage life, and market proximity; and (3) good plant health, suitable for organic cultivation. However, the main limiting factors for fruit tree production in greenhouse conditions to take into account are: (1) light scarcity at high latitudes; (2) a lack of cold for bud breaking, flowering, and fruit production; (3) potentially excessive temperatures in warm regions, which reduce the photosynthesis rate; and (4) a reduction of fruit quality, coloring, and aroma compounds in certain warm conditions with light day/night temperature variations.
\end{abstract}

Keywords: Prunus; stone fruit trees; protected cultivation; greenhouse; dormancy; temperature; climate change; fruit quality

\section{Introduction}

The cultivation of stone fruit trees (Prunus spp.) has nearly always been carried out in the field, outdoors, with some exceptions, such as trees grown in gardens or for ornamental purposes [1-4]. Stone fruit trees are typically grown in large production orchards in the open air, where there are many factors that can negatively impact the harvest, such as weather conditions, weeds, and pests, amongst others. In this type of orchard, farmers often opt for large-scale production, which often implies lower quality products, and the environment and fruit quality often get neglected. In conventional cultivation, fruit farms typically follow a common or habitual strategy rather than pursuing specific objectives to differentiate themselves from other farms. For more or less four decades, this has been the production strategy followed by the majority of fruit farms, despite appreciable differences 
in the degree of applied knowledge among the farms. In the analysis of a conventional fruit farm, the concept of productivity is of particular interest as an indicator of efficiency, both in terms of plantation and fruit production, since it implies a reference to yield $[2,3]$.

In this conventional production strategy, not all interactions between production factors are considered in an integrated way, and, above all, achieving a balance in the planting environment is not considered a priority [3]. Likewise, little or no attention is paid to some important aspects of fruit production, since the goal is to obtain a large amount of fruit, without taking into account other factors, such as fruit health and size, organoleptic properties and pesticide residues. Among the most significant factors limiting fruit tree production, we can include a lack of sunlight, temperature inconsistency, a surplus or loss of moisture, weed growth, wind speed, reduced carbon dioxide levels in some areas, low caliber fruits in cold areas, pest and disease infection in open air conditions, the effect of strange odors and flavors, and late maturity. These restrictions, mainly in cold areas, are related to abiotic stress, due to changing climatic conditions, and biotic stress, and they can be minimized by protected fruit tree cultivation [5].

Protected fruit tree cultivation is a specialized form of horticulture. Using greenhouses makes it possible to extend cultivation cycles in order to produce more favorable conditions, increase productivity and quality, and extend cultivation to new areas. These factors are the keys to success in the cultivation of temperate Prunus species, mainly peach (P. persica (L.) Batsch) and to a lesser degree apricot (P. armeniaca L.), in forced greenhouse conditions. Specific characteristics of certain fruit trees, including their perennial nature, their size, or their need to accumulate cold hours to sprout, pose new challenges. In countries like Japan (Shizuoka and Nigata prefectures), Korea (Wanju County), China (in the Provinces of Henan and Shandong), Italy (Region of Naples and Sicilia), and Spain (in the Province of Huelva, Southwest of Spain), greenhouse cultivation is common, but mainly for tropical and subtropical trees, and to a lesser degree in the case of peach and apricot species (Figure 1).

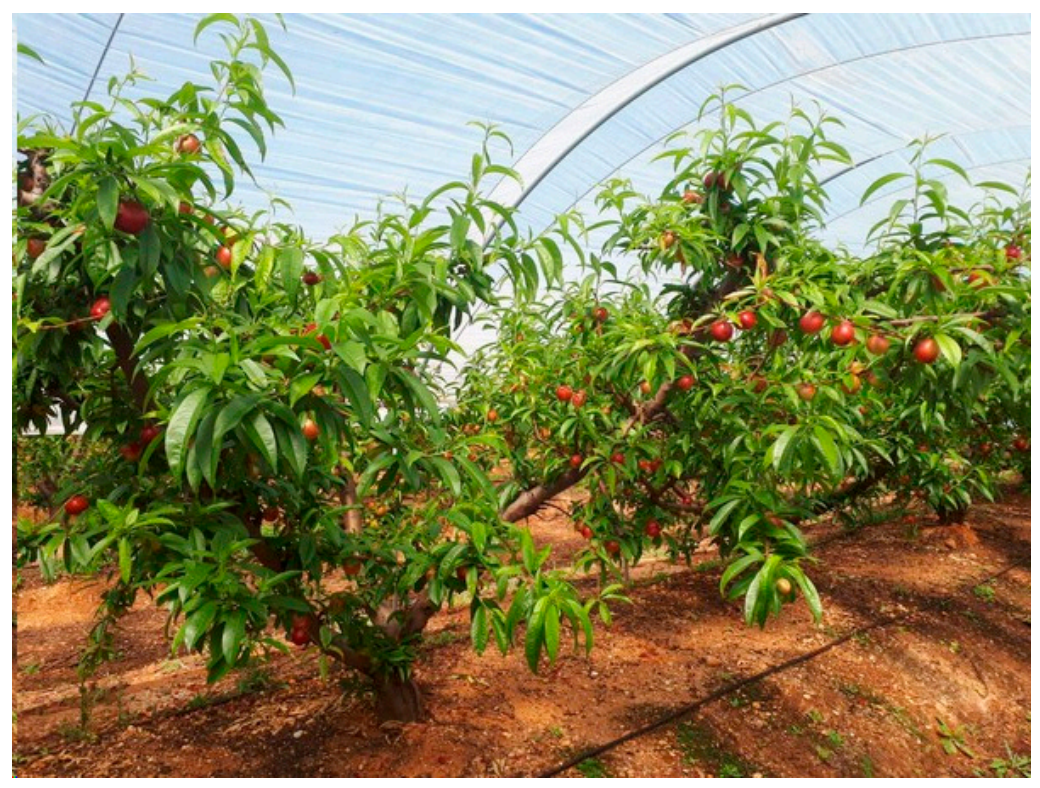

Figure 1. Detail of peach cultivation in greenhouse conditions in Huelva, southwest of Spain (www.freshplaza.es (accessed on 24 February 2021)).

China, the main producer, has approximately 20,000 hectares of peaches and several hundred hectares of apricot in protected cultivation in the provinces of Henan, Liaoning, Hebei, and Shandong [6-8]. In Japan, peach production is more limited with a total surface area of around 10,000 hectares spread around the country, and with high quality production in small paper bags in some cases, whereas in Korea commercial production is 
more limited $[9,10]$. In Spain, around 1000 hectares of peach production in greenhouses have been described in the Province of Huelva, with production of apricot starting in these conditions [11]. Finally, Italy is the other country where peach production has been described in the regions of Naples and Sicilia [12].

In these countries, peach and apricot production studies have taken a step beyond the evaluation of technological possibilities, and focused on the effect of certain parameters on the quality of stone fruits produced under greenhouse conditions [12-15]. However, there are few research references for Prunus cultivation under greenhouse conditions. During the 1970s, the first protected cultivation experiments were carried out in Italy using peach trees, and the crops were subsequently continued [12,14]. Later, further experiments were carried out, mainly in Japan and China, and mainly in apricot. At this moment, however, interest in this cultivation is increasing, in the context of climate change and new commercial opportunities derived from the securing supply in the face of demand.

Protected cultivation is a method of protecting fruit trees from adverse stresses and providing appropriate growth conditions. This cultivation technique provides numerous benefits, such as distributing labor more uniformly throughout the year owing to the diversified cropping season and climate conditions, minimizing the need for pathogen control, and avoiding adverse weather conditions. All of these benefits result in consistently good yields, excellent fruit quality, and early production, among other advantages [8]. The control of pests and diseases, and unique market opportunities are also important aspects of these cultivation systems. The high yields may make this production method a permanent alternative for fruit producers in cities, where production restrictions such as minimal land due to urbanization and pesticide use constraints make orchard production harder. The fact that greenhouse-grown fruit trees produce consistently better quality fruits and cost less than field-produced fruit trees thus makes greenhouse cultivation a promising alternative to field cultivation [15]. However, negative factors limiting apricot and peach production in greenhouse conditions have also been described, including light scarcity, a lack of cold for flower bud breaking, and excessive temperatures $[9,15]$.

The goal of this review was therefore to discuss the viability of cultivating apricot and peach trees in protected environments, while also discussing the unique physiological nuances of orchard culture in these protected environments. This new approach is of special interest since it entails cultivation in controlled warmer conditions to increase competitiveness, and mainly in cold regions.

\section{Main Factors Involved in the Cultivation of Fruit Trees in the Greenhouse}

The establishment of new fruit plantations, driven, in most cases, by new technologies and irrigation systems, continues to promote the parallel development of other sectors and activities, with the subsequent development of the entire rural environment. New agricultural technologies developed in recent decades have contributed to an unprecedented growth in world food production. However, there is growing concern that the conventional production model and the trajectory of agricultural development may not be the best, or the only, alternative for the future. Fruit production systems have been evolving in parallel with agricultural development in general, but there are great differences between areas, as some have more innovations or very different cultivation possibilities. There is a highly diverse array of practices currently in use, ranging from those used by the ancient Chinese, Japanese, Greeks, and Romans to distinctly modern practices requiring satellites in orbit [16].

There are alternatives to extensive conventional cultivation, including the strategy we are discussing here: the organic cultivation of stone fruits in controlled greenhouse conditions. Fundamentally, this strategy entails cultivation without the application of synthetic chemicals such as fertilizers, pesticides, phytoregulators, etc. The main factors involved in the cultivation of fruit trees in greenhouse planting systems include environmental management (temperature, humidity, solar radiation, and $\mathrm{CO}_{2}$ concentrations); plant material 
selection (cultivar and rootstock); and tree management (planting system and substrates, pollination, pruning, and stem girding) (Figure 2).

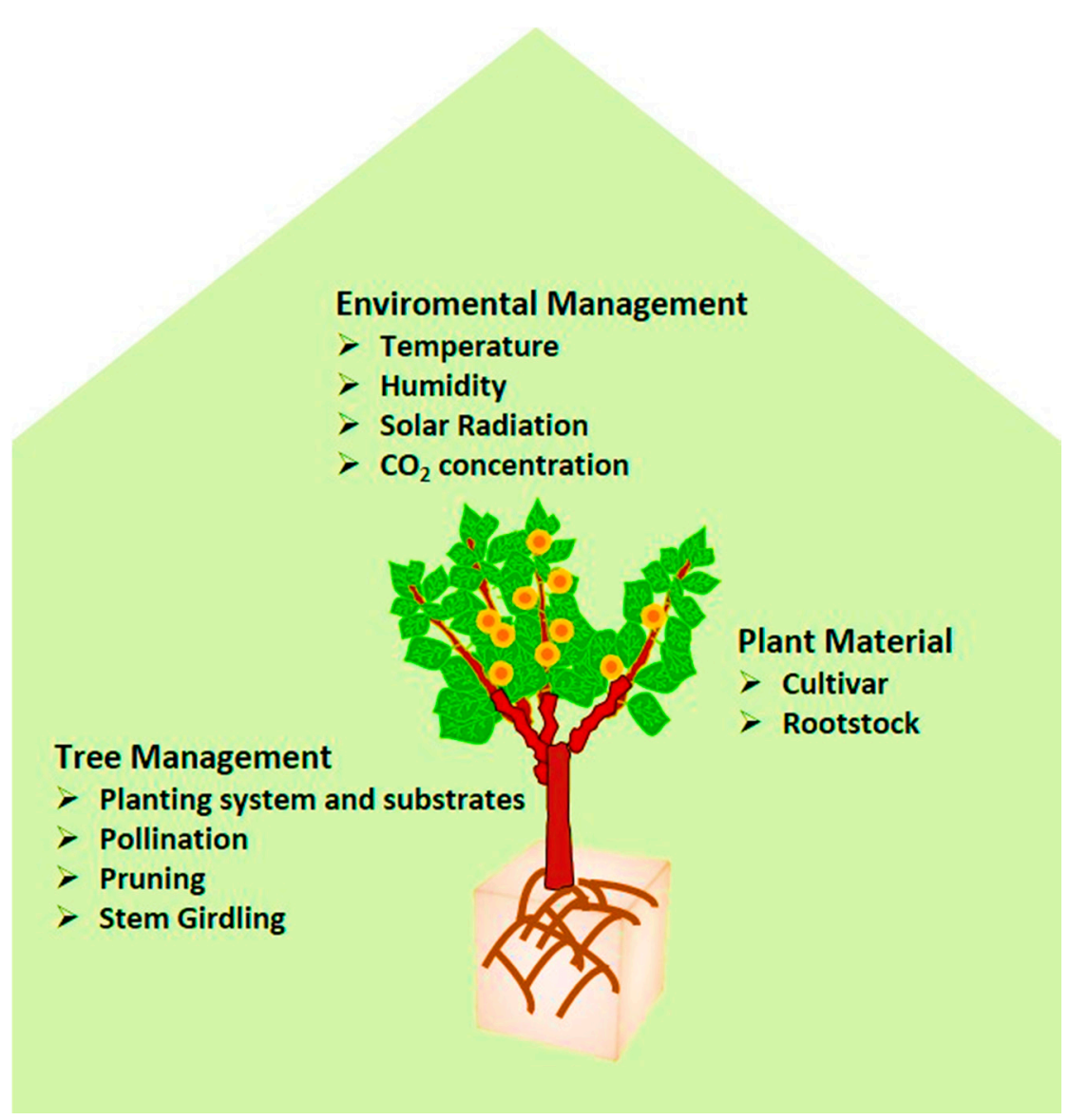

Figure 2. Main factors involved in the cultivation of fruit trees in the greenhouse.

\subsection{Planting Systems and Growth Substrates}

In greenhouse fruit tree cultivation, owing to the high costs of the protective structures, it is very important to choose planting methods that take the tree size into account and make it possible to rapidly attain good fruit production and yields. One of the most efficient agricultural solutions thus far has been to decrease the amount of space between trees. Due to the correlation between shoot and root growth in fruit trees, root restriction in small spaces progressively reduces vegetative vigor in the canopy of tree. Furthermore, the relation between the decrease in vigor and the beginning of the reproductive period in young trees makes it possible to increase planting density, which has another significant effect: the early production of fruit trees [12].

For example, a planting method that has proven successful in greenhouse peach is that of Y-trained fruit trees that vary from $4.5 \pm 5.0 \mathrm{~m}$ between rows and $1.0 \pm 1.2 \mathrm{~m}$ between trees. This method enhanced the planting density from 1500 to 5000 trees per ha. Ytraining has also proven to be an excellent training system for field-grown trees; the splitting of the tree canopy into two thin proliferous leaning walls magnifies light prevention, improves light distribution within the tree canopy, and enhances the delivery of photoassimilates to the fruits. Thanks to these features, this training system produces great yields and good product quality. Moreover, the decrease in spacing between the plants along the rows did not lead to a decrease in red blush on the skin. The pruning carried out three weeks before harvest was surely a synergetic parameter of these results; this strategy in the orchard has proven to be very efficient for improving and modifying fruit color [12]. 
Soil moisture and relative humidity is primarily regulated by supplemental irrigation. Proper ventilation and irrigation management helps to limit foliar disease development. In addition, in planting systems for woody plants the substrate is the key to success, since it must provide sufficient aeration, texture, and moisture retention for adequate root development [17]. The substrates must have a field capacity that ensures the water needs of the crops are met. For peat substrate, for example, the porosity was found to be closely correlated with the plant growth of Prunus $\times$ cistena sp. [18]. Hydroponic cultivation is also the best alternative to peat. It is necessary to develop novel hydroponic or semi-hydroponic systems for woody trees that make it possible to control nutrition, growth, and fruit quality. The development of new substrate formulations that improve fruit tree nutrition in hydroponic and semi-hydroponic systems is therefore of great interest, together with the development of novel containers for hydroponic cultivation that enable us to control the nutrition and root growth of woody trees [19]. Abnormal growths of roots can occur due to the limited space in containers, as can unwanted constrictions due to the tree weight with a greater overloading during the phenological stage of fruit production. In addition, to achieve adequate crop development in different hydroponic and semi-hydroponic media, plant nutrition and irrigation must be fully controlled. It is necessary to develop automated irrigation technologies to efficiently control fertilizers in the irrigation network, injecting the adequate amounts to satisfy the nutritional needs of stone fruit trees in hydroponic and semi-hydroponic systems [20,21].

\subsection{Rootstock and Cultivar Selection}

The selection of adequate plant material (rootstocks and cultivars) is of utmost importance in greenhouse fruit tree cultivation, in terms of both production and yield [22]. A large tree size, for instance, has been one of the biggest limiting factors for growing fruit trees in greenhouses. As a result, greater control of tree size via dwarfing patterns and advances in training systems has opened new possibilities for this type of cultivation.

Regarding cultivar selection, since most fruit tree cultivars are self-incompatible [23], pollination problems will occur if these self-incompatible cultivars are planted in the greenhouse without bees or pollinizers within the rows [24,25]. In controlled conditions, the cultivation of self-incompatible Prunus cultivars must be compensated for with the introduction of natural pollinators. Alternatively, the cultivation of self-compatible Prunus genotypes is another solution to the lack of insect pollination in greenhouse conditions. A fruit tree variety that is self-compatible is therefore desirable for greenhouse cultivation $[15,26]$. Cultivars whose fruits get higher prices in the market are good choices for greenhouse cultivation, as are early maturing cultivars. Tree size is another aspect to consider. For fruit trees that accept shrub training or dwarf trees, a low roof is suitable. For example, a greenhouse less than three-meters high is suitable for fig trees [9].

Obtaining stone fruits through new intensive cultivation systems without soil also requires new cultivars with reduced chilling requirements for breaking bud dormancy. If these chilling requirements are not met, the buds will not blossom or the sprouts will not grow well. Forced chilling has been found to be effective when growers want to break dormancy in the short term. If forced chilling is performed, it is essential to closely monitor the temperatures inside the greenhouse and to open windows, doors, and vents at night, when external temperatures are favorable, and provide shade during the day, to ensure that the temperature does not rise above $7.2{ }^{\circ} \mathrm{C}$ for too long. A period of $6-8$ weeks is enough to supplement chilling requirements and allow apricot trees to begin their fruiting phase sooner than they would outdoors [15].

Chilling requirements are another of the most important aspects in cultivar selection. Temperatures of between approximately $2{ }^{\circ} \mathrm{C}$ and $12{ }^{\circ} \mathrm{C}$ provide the chilling requirements for apricot trees, although the requirements vary between different cultivars, as well as in different years. Daily temperatures of $10{ }^{\circ} \mathrm{C}$ and higher for 4 or more hours can neutralize the chilling requirements a plant has received in the previous 24 to $36 \mathrm{~h} \mathrm{[15].}$ Cultivars with low chill requirements can be planted in colder areas under greenhouse 
conditions. In warmer areas very low chilling-requirement cultivars should be the solution, combining chill accumulation inside the greenhouse and chilling requirements of the Prunus cultivars [27]. In addition, the development and selection of new early market (low chill, short fruit development period) cultivars or very late cultivars (high chill, long fruit development period) with a high quality will expand the market window and help ensure ongoing profitability.

\subsection{Pollination Management}

Suitable pollination is necessary for optimal fruit set and production. The pollination of fruit tree flowers (Figure 3) is aided by insects and the wind. However, in a greenhouse, the activity of these natural factors is limited. If there is inadequate pollination at the time of flowering, productivity will be minimal. Honeybees play a vital role in the pollination for fruit trees like apricot trees, which are self-sterile and dependent on pollinators. If pollination were limited for some reason, decreased fruit set could occur. Adverse weather conditions may limit bee activity, which is highly climate-dependent. If bees fly infrequently between fruit trees, cross pollination by bees would logically diminish [15]. Additionally, high temperatures reduce the rate of floral differentiation, affecting the final yield in the following years in peach [28].
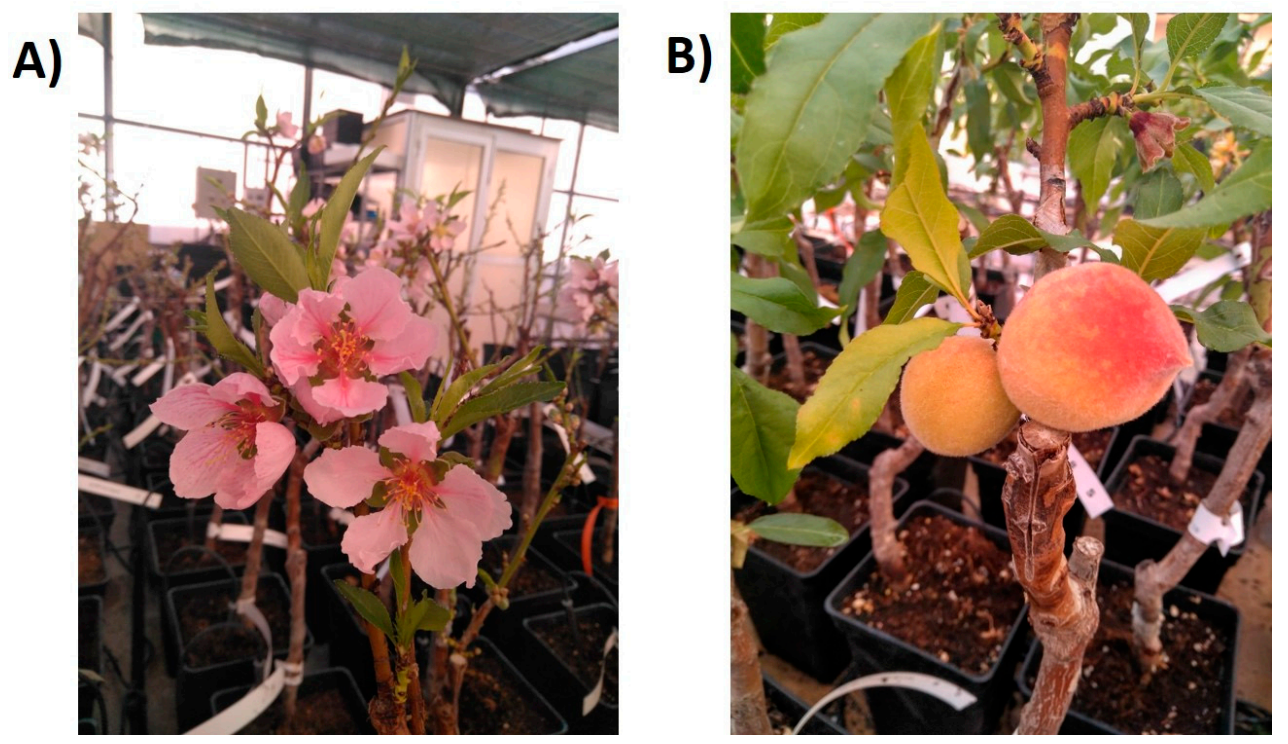

Figure 3. (A) Peach flowers recently opened in the controlled greenhouse cultivation of peach trees for research purposes in Murcia, southwest of Spain, in January. (B) Detail of peach fruits in the controlled greenhouse cultivation of trees for research purposes in Murcia, southwest of Spain, in March.

In greenhouse conditions, mason bees and bumblebees are used for pollination, as they tend to operate better in cooler temperatures and cloudy weather than honeybees. Mason bees and bumblebees are relatively calm and do not sting unless disturbed (mason bees never sting). As a result, honeybees have been replaced by mason bees or bumblebees in greenhouse fruit tree cultivation, and mason bee pollination has subsequently become a standard method. Proper pollinizers should be selected with care when beginning a greenhouse business. In the field, self-incompatibility in fruit trees is compensated for by planting pollinizers in close vicinity to the primary cultivars. This strategy should be followed in the greenhouse, and pollinizers should account for one-quarter of the number of primary cultivars within the plots [15].

Alternatively, as mentioned before, the use of self-compatible or self-fertile Prunus cultivars will produce a suitable pollination and production without a reduction of fruit 
attributes [29]. Although the use of natural pollinations should also be of interest from a production point of view [30].

\subsection{Summer Pruning and Stem Girdling}

Summer pruning regulates tree size and enhances flowering and fruiting. Researchers have demonstrated the effect of summer pruning on apricot tree flowering, and have found that responses to flowering and fruiting depend on the timing of top elimination. When the length of the new branches was $25-30 \mathrm{~cm}$ at the time of summer pruning, the formation of flower buds was greater than when the length of the new shoots was $40 \mathrm{~cm}$ or more. Summer pruning occurs in late June or early July in the Northern Hemisphere. Stem girdling in late June or early July has also shown a positive effect on controlling tree size and promoting flowering. Stem girdling restricted the growth of trees and enhanced the number of flower buds compared to non-girdled trees [31]. Besides pruning, tree size is limited by the artificial application of drought stress, root pruning, and the use of dwarfing and semi-dwarfing scion and rootstock cultivars. Other practices employed in this system include girdling in the fall [12]. Specific labor and equipment requirements are necessary to perform these tasks in controlled and reduced conditions. This mean a new culture of apricot and peach production in new conditions, with greater requirements linked with greater benefits [32].

From a commercial point of view, different practical measures need to be taken to maximize fruit yield and quality per unit of land area, while ensuring that trees do not get too big. One such practice is called postharvest canopy removal. This practice is a modified summer pruning technique. It begins immediately after harvest with the removal of all current shoots. New shoots that emerge thereafter are "tipped" several times to stimulate flower bud production [13].

\subsection{Temperature and Humidity Control}

After the chilling requirements of both the main cultivars and pollinizers have been fulfilled by natural chilling or forced chilling, the trees should be cared for following ordinary greenhouse management practices. In apricot, for example, the primary temperatures in the greenhouse should be maintained at $5-6{ }^{\circ} \mathrm{C}$ at night, and at about $26-28{ }^{\circ} \mathrm{C}$ in the daytime. Under such conditions, the trees will flower after approximately 5-6 weeks. The recommended temperature for full blooming is $22-25^{\circ} \mathrm{C}$ in the daytime and not lower than $8{ }^{\circ} \mathrm{C}$ at night. The temperature of the greenhouse floor is lower at night than during the day, so covering the floor with white or black plastic mulch can increase the temperature in the greenhouse. Before flowering, relative humidity can be between $60-80 \%$, but after flowering it should not be higher than $60 \%$ in apricot [15]. In addition, control of both temperature and humidity should be handled by retractable films or temporary structures, although this solution can increase production costs.

Greenhouse microclimate (i.e., illumination, temperature, water, humidity, etc.) should be monitored and controlled. The use of more transparent films on the outside of the structure, plus the use of reflective films on the greenhouse floor, enhances the light environment. Temperature regulation during bloom and during the fruit ripening period can result in ripening acceleration from 10 to 50 days [13].

\subsection{Solar Radiation, Photosynthetic Capacity, and Carbon Dioxide Concentration}

Due to the greenhouse structure, the intensity of the sunlight inside only reaches about $60-70 \%$ of that found outdoors. Moreover, the amount of sunlight varies in different parts of the greenhouse; the amount in the southern and middle parts (85\%) is greater than that in the northern part $(44 \%)$. The lower sunlight intensity will decrease fruit quality, especially in the northern section of the greenhouse. It is therefore necessary to improve the optical conditions by, for example, keeping the covering of the greenhouse clean so that the sunlight can easily penetrate [15]. 
Regarding photosynthetic capacity, nectarine (P. persica (L.) Batsch var. nucipersica or var. nectarine) has shown suitable acclimation to solar-heated greenhouse growth conditions. Compared to open-field-grown plants, a significant increase was found in the daily average net photosynthetic rate in the greenhouse-grown nectarines. In addition, the diurnal variation of maximum photochemical efficiency of Photosystem II (Fv/Fm) indicated that the plants grown in greenhouse conditions had less photoinhibition than in open-field conditions. A decrease in the chlorophyll (chl) a/b ratio and a significant increase in chlorophyll (chl) b content in the leaves of greenhouse-grown plants was also observed [33]. In apricot, greenhouse studies have also found an increase in photosynthetic capacity when the temperature was around $25^{\circ} \mathrm{C}$. Moreover, the functions of both photosystem I (PS I) and photosystem II (PS II) were improved by the high temperatures and intense light [34]. The protected environment was useful in maintaining a relatively high temperature, and avoiding leaf injury due to environmental factors, resulting in a longer period of photosynthetic activity, which increased the photosynthetic production [9].

Finally, the atmospheric carbon dioxide concentration in a greenhouse is about $300 \mathrm{~mL} . \mathrm{m}^{-3}$, which is normal for plant growth. However, if the greenhouse lacks air exchange with the outdoors, and there is no extra supply of carbon dioxide when the sun rises, the concentration is often lower. Studies have shown that high carbon dioxide concentrations lead to increased growth and photosynthesis, especially when nutrients are sufficient for the plant. Plants can therefore improve their nutrient supply in the presence of high $\mathrm{CO}_{2}$ levels. The extra amount of carbon dioxide can increase yields by up to $15 \%$, but it can be hard to keep the gas inside the greenhouse, as most are not well sealed, and there is significant potential for $\mathrm{CO}_{2}$ leakage. Using organic fertilizers in the greenhouse increases the concentration of $\mathrm{CO}_{2}$ to a certain degree, however, and is a widely used method [15].

\section{Main Benefits of Planting Fruit Trees in the Greenhouse}

The establishment of fruit plantations in the greenhouse makes it possible to extend production areas and growing cycles, and improve fruit quality, thus allowing for a stable supply of high-quality products to the market. The greenhouse protects crops from extreme temperatures and ensures optimal ambient temperature and humidity for crop development. In addition, greenhouses can reduce the incidence of pests and diseases, facilitate weed control, and protect crops from wind, hail, and sunscald. Soilless crops also provide a number of advantages in protected environments, and they contribute to reducing the harmful impacts of peat extraction. Soilless systems are totally novel in fruit tree cultivation in Spain, although there are no protected and hydroponic production systems for stone fruit trees yet. There have been some studies performed on citrus fruits, such as orange, lemon, and tangerine grown in pots, although this approach has not been developed on a larger scale, i.e., at the farm level. It is well known that this type of plant is tropical and is well adapted to very hot environments, whose thermal requirement is considerably greater than that of stone fruit trees. In addition, this crop does not need cold hours for fruit production [35]. In this context, a project proposing the cultivation of Spanish and Paraguayan varieties of white meat peach, apricot, and nectarine in controlled soil and climate conditions is clearly of great interest. These new cultivation techniques can also improve the adaptation of these varieties to the cultivation conditions in warm areas, and can improve their profitability in terms of fruit quality and earliness.

\subsection{Precocity and Time of Harvesting}

Cultivation in controlled conditions clearly increases precocity in fruits [35] (Figure 3). Greenhouse-grown apricots ripen in mid-April and continue until mid-May, which is 50-60 days earlier than the ripening time of orchard-grown apricots, allowing growers to arrive early to the market. Moreover, the rate of photosynthesis and yield of satsuma mandarins were higher under greenhouse cultivation than in the field. Controlled greenhouse conditions also favor food safety, making it easier to label and certify fruits [36]. In addition, greenhouse cultivation increases the harvest duration by controlling environ- 
mental factors [5]. For example, the harvest time of grape (Vitis vinifera L.) cultivated in a greenhouse could be controlled to stretch from the beginning of April to the end of August, whilst the harvest time of grape in the field only occurred in the middle or at the end of August [37]. In the case of apricot and peach species, precocity and an increased harvest duration have also been observed in greenhouse-grown peach $[13,38]$.

\subsection{Fruit Quality, Storage Life, and Market Proximity}

There is uneven horizontal light distribution in greenhouses, and the light intensity is lower in the northern zone than in the southern zone. Accordingly, the color and soluble solids content of nectarine fruits on the upper parts of trees in greenhouses were found to be higher than in fruits on the lower parts of the trees [39]. This is because the sunlight intensity varies between the upper and lower layers of the canopy, so the color and soluble solids content in the outer parts of the tree and the parts in the shade are significantly different. The weight and average diameter of nectarine fruits were lower in the upper parts of the tree, however, than in fruits in the middle parts of the tree. Moreover, photosynthetic active radiation was greater in the upper parts of the tree than in the middle and lower parts $[40,41]$. Researchers have also shown that shade does not reduce the weight of peach fruit. Therefore, the canopy position is somewhat independent of photosynthetic active radiation (PAR) [42].

In addition, the use of hydroponic and semi-hydroponic techniques in protected greenhouse conditions should result in fruits with a high organoleptic quality and caliber. Improved fruit quality parameters include texture, taste, smell, and size, which will satisfy consumer needs and open new commercial windows. Even the use of hydroponic solutions derived from organic farming, such as manure, could improve fruit quality. To give an example, one study compared the effects of a goat manure-derived hydroponic nutrient solution, a commercial solution, and tap water used as hydroponic solutions in tomato cultivation [43]. The hydroponic solution from goat manure led to a higher lycopene content, which gave the fruit a greater antioxidant capacity and thus boosted its health attributes. In another study, the use of a plastic cover for up to 6 weeks before harvesting was found to increase the fruit yield and shelf life of apricot fruit. However, if the plastic coating was left until harvesting, the apricot color was reduced [44]. As for crops like sweet cherry (P. avium L.), plastic covers used in Nordic countries weeks before harvest were found to reduce cracking and fungi presence, and therefore favored a longer shelf-life period [45].

\subsection{Pests, Diseases Control, and Organic Culture}

Controlling the agronomic conditions in greenhouses produces a decrease in plant pathologies and competing agents, and this decrease can increase yields and make it easier to obtain consistently high-quality fruits [46]. Such protected cultivation is of particular interest in organic fruit production. In cherry, for example, problems like fruit cracking and bruising due to rain, bird attacks, hail, and spring frost damage have been solved with protected environments [47]. In addition, plastic covers favor a reduced use of chemical treatments, especially fungicides. In grapes grown in the greenhouse, for instance, anthracnose disease incidence was lower than in grapes planted in the field [48]. Such aseptic conditions in controlled greenhouse environments have been used in the evaluation of virus and viroid resistance in different Prunus species [49-51]. Moreover, controlled greenhouse conditions allow for a double growth cycle, so we can perform two evaluation cycles per year [52] (Figure 4). Other authors have evaluated Prunus genotypes for resistance and tolerance against different nematode species in greenhouse conditions [53-55]. 
A)

B)
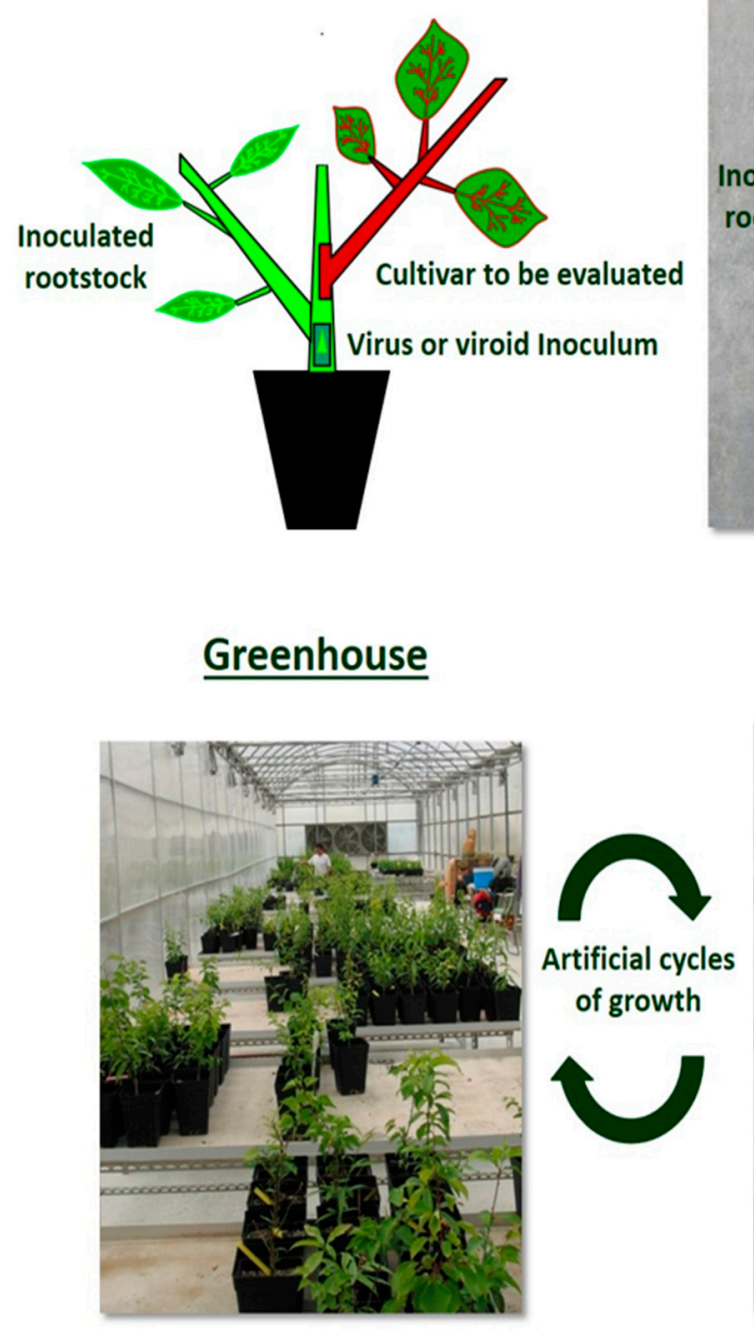

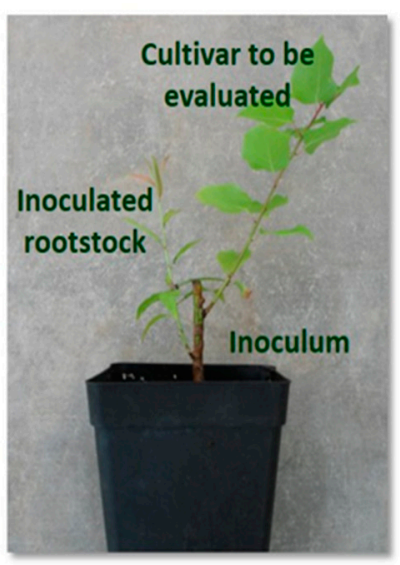

Cold chamber

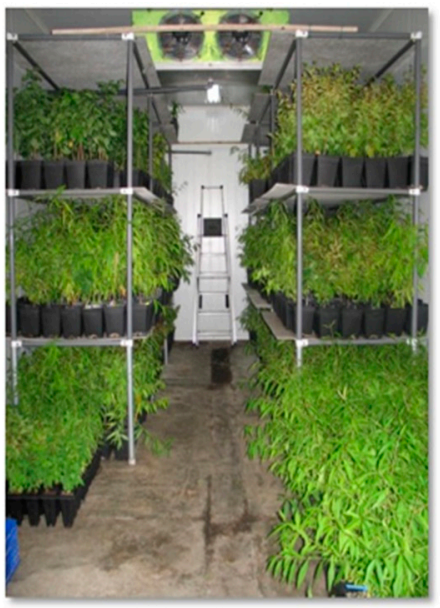

Figure 4. (A) Details of the model plant used in a virus and viroid resistance evaluation protocol in Prunus species in controlled greenhouse conditions. (B) A general view of the growth of Prunus species in Spain in the virus and viroid resistance evaluation. Two artificial cycles of growth are possible per year in alternating periods of 4 months in the greenhouse, and also in the cold chamber at $4{ }^{\circ} \mathrm{C}$ in darkness for 2 months.

\section{Main Handicaps of Production in the Greenhouse}

\subsection{Light Scarcity in High Latitudes}

In greenhouse production, high density planting is usually used to increase yield per unit area. Greenhouse trees have been found to produce more vigorous shoots, leading to a thicker canopy compared to that of orchards. Moreover, the fruit growth cycle in most greenhouse trees (such as peach) ranges from winter to spring, when the intensity of sunlight in orchards is not as high as in other seasons. All the factors mentioned above result in a poor light environment within the tree canopy. This situation is more complicated in Prunus cultivation at high latitudes [40].

In the greenhouse production of nectarine, a canopy thickness of 75 to $100 \mathrm{~cm}$ has been found to be optimum, and may be obtained by pruning in the summer. Previous research in open field conditions has indicated that a canopy thickness ranging from 150 to $180 \mathrm{~cm}$ is optimal for peach trees. While in the greenhouse, with lower light intensity and more powerful tree growth, a thinner canopy is needed to retain good canopy light in comparison with an orchard. Summer pruning is also essential for controlling the canopy in the third stage of peach fruit growth so that the light can penetrate it [40]. A decrease in the chlorophyll (chl) a/b ratio and the functions of both PS I and PS II, along with a decrease 
in chlorophyll (chl) b content, have also been observed in nectarine [33] and apricot [34], linked to a reduction of light intensity in greenhouse conditions.

\subsection{How to Break Bud Dormancy in Greenhouse Conditions?}

One of the main challenges of growing fruit trees in the greenhouse is providing the necessary chilling requirements. When the daytime temperature is greater than $19^{\circ} \mathrm{C}$, the chilling requirements of the fruit trees are not met. Chill hours must therefore be provided artificially, using evaporative cooling, which can reduce the temperature of the bud and decrease the negative effect of high temperatures. To do this, intermittent microsprinklers are installed in the greenhouse where fruit trees are grown to reduce the bud temperature through evaporative cooling, and thermostats are installed to keep the greenhouse temperatures below a maximum threshold of $18^{\circ} \mathrm{C}$ [56].

The election of a suitable cultivars with suitable chilling requirements is of great interest, as we mentioned before $[27,57]$. However, the chilling requirements can also be altered with chemicals such as mineral oils, dinitro-o-cresol, calcium cyanamide $\left(\mathrm{CaCN}_{2}\right)$, and hydrogen cyanamide $\left(\mathrm{H}_{2} \mathrm{CN}_{2}\right)$ [58]. In addition, trees can be sprayed to break dormancy in order to save time. In one study, when three-quarters of the chilling requirements of peach trees were satisfied, the trees were sprayed with oil-DNOC (Dinitro-ortho-cresol) to break dormancy in warm conditions. The orchards were covered with polyethylene sheets before being sprayed, which enhances the spraying effect considerably on sunny days when the temperature reaches $24^{\circ} \mathrm{C}$ or higher [56]. The use of temporary structures which can be opened during winter is an alternative, although this solution can increase production costs, while also increasing the risk of pest and disease infections.

The use of fresh garlic paste and commercial garlic oil has been found to be potentially effective in providing the chilling requirements in grapes, perhaps due to the presence of diallyl disulfide in garlic. Garlic paste can thus be used as a non-toxic substitute for $\mathrm{CaCN}_{2}$ and $\mathrm{H}_{2} \mathrm{CN}_{2}$ [58]. Diallyl disulfide has also been used in apple tree bud break in greenhouse conditions [33]. In most regions where grape vines are grown, the issue of how to break bud dormancy during the summer must be solved before double cropping is possible [58].

Forced flowering in greenhouses is also of great interest from a market perspective, since it prevents poor bud break and abnormal blooming. It is important to keep in mind that trees cultivated under greenhouse conditions typically have lower chilling requirements than orchard-grown trees. This trait requires lower concentrations of potentially harmful chemical compounds like mineral oils, diatomaceous compounds, $\mathrm{KNO}_{3}$, thiourea, cyanamides, and thidiazuron, which are used to provoke budding [59].

However, the moment of application of these biostimulants for breaking dormancy is critical for success, and depends on the endodormancy state of the flower bud and its transition to ecodormancy [60]. Treatments with these biostimulants should be applied at the optimum time for endodormancy release, as they can be null or even toxic, depending on the state of the bud [61]. Monitoring of breaking dormancy is of great interest in terms of the use and optimization of biostimulants to promote flowering in Prunus tree species in the controlled greenhouse conditions and warming context [62,63].

\subsection{High Temperature in Greenhouse in Warm Conditions}

Temperature is an important factor in producing a crop and in controlling fruit quality. A common mistake is to maintain high temperatures in the greenhouse, where temperatures above $35^{\circ} \mathrm{C}$ can easily occur on sunny days in a closed system. High temperatures during bloom and fruit development are harmful, and lead to no fruit set or fruitlet drop $[31,56]$. In peach trees, at the time of blooming, the temperature should not be higher than $23^{\circ} \mathrm{C}$. During the 2 to 3 weeks before blooming, high temperatures have a negative effect on fruit development, and cause increased vegetative growth. After bud break, the greenhouse temperature should not exceed $25^{\circ} \mathrm{C}$. The temperature should only be allowed to reach $30{ }^{\circ} \mathrm{C}$ when the diameter of the fruit has reached $2 \mathrm{~cm}$. Using this method, high quality peach and nectarine fruits have been observed, and fruits were harvested at the end of 
March [56]. In nectarine, high temperatures produced a decrease in the chlorophyll (chl) $\mathrm{a} / \mathrm{b}$ ratio in the leaves of greenhouse-grown plants, along with a decrease in the chlorophyll (chl) b content [33].

The higher temperatures in protected systems can also cause root suffocation [33]. In this context, the installation of shading nets, plastic covers, or sprinkler air conditioning should help to control excessive temperatures. The use of temporary structures which can be opened during summer is an alternative, although this solution can increase production costs, and also increases the risk of pest and disease infection [38].

\subsection{The Amount of $\mathrm{CO}_{2}$}

Photosynthesis is a major process in plants, and $\mathrm{CO}_{2}$ is the substrate for photosynthesis, so its concentration therefore has a significant impact on fruit development [64]. It has been observed that the amount of carbon dioxide $\left(\mathrm{CO}_{2}\right)$ in greenhouses rises above the mean value at night, but decreases below 200 ppm during the day, especially from 10 a.m. to 2 p.m. [64]. Therefore, low carbon dioxide levels may be a limiting factor for planting trees in the greenhouse. To counteract such effects in the greenhouse, carbon dioxide enrichment has been used for many horticultural products such as grapes, peaches, strawberries, and tomatoes [65]. Peach trees exposed to $\mathrm{CO}_{2}$ have a higher photosynthesis rate than other peach trees, and similar results have been reported in the case of sour orange [66]. Generating $\mathrm{CO}_{2}$ concentrations of up to $360 \mathrm{ppm}$ in the greenhouse via $\mathrm{CO}_{2}$ enrichment can compensate for the lack of this gas in the greenhouse and change the taste of the fruit with respect to the control group. $\mathrm{CO}_{2}$ enrichment has also been found to increase the dominant sugar content of greenhouse-grown peaches (sucrose and fructose). The aromas of lactones of norisoprenoids also increase when this method is used. Moreover, the levels of malic acid and hexanol emissions drop in peach fruits. Using this method in a greenhouse can therefore increase consumer satisfaction.

\subsection{Fruit Quality, Coloring, and Aroma Compounds}

When orchards are covered with polyethylene sheets, which allow ultraviolet (UV) radiation to pass through, anthocyanin pigments develop in the fruit skin. All polyethylene sheets are enriched with UV-absorbers to enhance their resistance to UV radiation. This leads to minimal transmission of UV light, resulting in light red skin on peach and nectarine fruits grown under these plastic covers mainly in warmer conditions, with light day/night temperature variations inside the greenhouse [56]. Fruit quality is improved by large temperature differences between day and night [7].

There are few comparative studies on the aromas of fruits grown in open fields versus those grown in greenhouses, and the results are not very conclusive. A comparative study of the aromatic compounds in Cavendish bananas grown in the greenhouse and in open fields revealed totals of 76 and 80 compounds in the greenhouse-grown and field-grown bananas, respectively. Total concentrations of aromatic compounds were thus higher in the field-grown bananas. Esters were the most numerous aromatic compounds, followed by aldehydes. A total of 30 esters were identified in field-grown bananas, with a total concentration of $23.8 \mathrm{mg} / \mathrm{kg}$, and 28 were identified in the greenhouse-grown bananas, with a total concentration of $20.5 \mathrm{mg} / \mathrm{kg}$. Other aromatic compounds identified included ketones, volatile phenols, and terpene. Moreover, a sensory analysis of the bananas grown outdoors showed that they were more favored by consumers due to their aromatic qualities [67].

\section{Conclusions}

Fruit farms are looking for new production strategies that will allow them to face the future in a more advantageous position, and overcome the difficulties that this production sector has experienced for many years. In addition, increasing competitiveness in the sector and the feared surpluses of production make it necessary to establish clear and increasingly specific objectives, which must be achieved through good planning and farm manage- 
ment. In this context, greenhouse cultivation is a novel method that not only protects crops from stress, but also improves production via high levels of specialization and higher quality products in order to satisfy consumer needs. Control of pests and diseases, and unique market opportunities are also important benefits of protected cultivation. The main factors involved in the successful cultivation of fruit trees in the greenhouse include planting systems and substrates, cultivar and rootstock selection, pollination management, and suitable environmental management. In terms of apricot and peach production in greenhouse conditions, excess temperatures reducing photosynthesis, and a lack of cold for bud breaking, are the most significant limiting factors. Nevertheless, forced fruit cultivation should provide a commercial opportunity where cultivation outdoors in the field would not be possible. Moreover, forced cultivation also makes it possible to obtain fruits of a high caliber and of exceptional organoleptic quality, especially in the case of white peaches, nectarines, apricots, and cherries, which have shown superior texture, taste, and smell with respect to competing products. In addition to the quality, the yield, season of cultivation, and export potential of the fruits can also be enhanced by greenhouse cultivation.

Author Contributions: Conceptualization, P.J.M.-G., P.M.-G. and S.R.D.; formal analysis, M.R. and J.A.S.; writing - original draft preparation, P.J.M.-G., P.M.-G. and S.R-D.; writing-review and editing, P.J.M.-G., P.M.-G., S.R.D., J.L.-A., M.R. and J.A.S. All authors have read and agreed to the published version of the manuscript.

Funding: This research was supported by the projects "Selection and characterization of drought resistant almond cultivars from the Mediterranean basin with high nutraceutical values" (Nut4Drought) of the ARIMNET-2 European Program, "Epigenetic regulation of the resistance to Plum pox virus (sharka) induced in peach by almond grafting and its application as interstock (ALMOND4SHARKA)" of the Spanish Ministry of Science, Education and Universities (RTI2018-095556-B-I00) and "Breeding stone fruit species assisted by molecular tools" from the Seneca Foundation of the Region of Murcia (19879/GERM/15).

Institutional Review Board Statement: Not applicable.

Informed Consent Statement: Not applicable.

Data Availability Statement: No new data were created or analyzed in this review study.

Acknowledgments: We would like to thank the two reviewers for their constructive comments, which helped us to improve the manuscript. We thank Khalil Rahimi Dvin and Mansureh Tamizgran for their grammatical corrections and valuable suggestions on this article.

Conflicts of Interest: The authors declare no conflict of interest. The funders had no role in the design of the study; in the collection, analyses, or interpretation of data; in the writing of the manuscript, or in the decision to publish the results.

\section{References}

1. Shaulis, N.J. Tree and soil response to cultural treatments of peach in South Central Pennsylvania. Proc. Am. Soc. Hortic. Sci. 1946, $48,26-31$.

2. Martínez-Gómez, P.; Sozzi, G.O.; Sánchez-Pérez, R.; Rubio, M.; Gradziel, T.M. New approaches to Prunus tree crop breeding. J. Food Agric. Environ. 2003, 1, 52-63.

3. Robinson, T.L. Recent advances and future directions in orchard planting systems. Acta Hortic. 2004, 732, 367-381. [CrossRef]

4. Slathia, D.; Reshi, M.; Hussain, S. Protected cultivation of ornamentals. Glob. J. Bio-Sci. Biotech. 2018, 7, $302-311$.

5. Aman, A.; Sinha, S.; Rajan, R. Potentiality of protected cultivation in fruit crops: An overview. J. Pharmacogn. Phytochem. 2018, 7, 3557-3560.

6. Peaches in Greenhouses in China. Available online: https://www.growingproduce.com/fruits/stone-fruit/peaches-ingreenhouses-in-china/ (accessed on 24 February 2021).

7. Layne, D.R.; Wang, Z.; Niu, L. Protected cultivation of peach and nectarine in China-Industry observations and assessments. J. Amer. Pomol. Soc. 2013, 6, 18-28.

8. Gao, H.; Wang, S.; Wang, J. Fruit protected cultivation in China. Acta Hortic. 2004, 633, 59-66. [CrossRef]

9. Kamota, F. Protected cultivation of fruit trees in Japan. J. Agric. Meteorol. 1987, 42, 391-395. [CrossRef]

10. Japan: Peaches Grow in Small Paper Bags. Available online: https://www.freshplaza.com/article/2098950/japan-peaches-growin-small-paper-bags / (accessed on 24 February 2021). 
11. España: Arranca la Cosecha de Las Primeras Nectarinas y Melocotones de Invernadero. Available online: https://www. freshplaza.es/article/9089931/espana-arranca-la-cosecha-de-las-primeras-nectarinas-y-melocotones-de-invernadero/ (accessed on 24 February 2021).

12. Caruso, T.; Giovannini, D.; Marra, F.P.; Sottile, F. Planting density, above-ground dry-matter partitioning and fruit quality in greenhouse-grown Flordaprince' peach (Prunus persica L. Batsch) trees trained to "free-standing Tatura". J. Hortic. Sci. Biotech. 1999, 74, 547-552. [CrossRef]

13. Zhang, H.; Gao, D.; Li, D.; Li, X. Studies on developments of quality physiology of peach in greenhouse. Chin. Agric. Sci. Bull. 2005, 28, 286-288.

14. Caruso, T.; Barone, E. Aspetti e problemi della peschicoltura protetta. Riv. Fruttic. 1993, 4, 43-53. (In Italian)

15. Haoyuan, S.; Yuzhu, W.; Li, Y.; Zhenru, L. Some factors influencing greenhouse apricot production in Beijing. In Proceedings of the 2nd Conference on Key Technology of Horticulture, Beijing, China, 17-18 July 2010; pp. 11-15.

16. Alganci, U.; Sertel, E.; Kaya, S.; Üstündağ, B. A research on agricultural mapping capabilities of the SPOT 6 satellite images. In Proceedings of the Second International Conference on Agro-Geoinformatics (Agro-Geoinformatics), Fairfax, VA, USA, 12-16 August 2013; pp. 93-96.

17. Gruda, N.; Qaryouti, M.M.; Leonardi, C. Growing media. In Good Agricultural Practices for Greenhouse Vegetable Crops; FAO: Rome, Italy, 2013; pp. 271-302.

18. Allaire, S.E.; Caron, J.; Duchesne, I.; Parent, L.E.; Rioux, J.A. Air-filled porosity, gas relative diffusivity and tortuosity: Indices of Prunus $\times$ cistena sp. growth in peat substrates. J. Am. Soc. Hortic. Sci. 1996, 121, 236-242. [CrossRef]

19. Savvas, D.; Gianquinto, G.; Tuzel, Y.; Gruda, N. Soilless culture. In Good Agricultural Practices for Greenhouse Vegetable Crops; FAO: Rome, Italy, 2013; pp. 303-354.

20. Jones, J.B. Hydroponics: A practical Guide for the Soilless Grower; CRC Press: New York, NY, USA, 2005; p. 352.

21. Keith, R. How-To Hydroponics; The Futuregarden, Inc.: New York, NY, USA, 2003; p. 435.

22. Leonardi, C.; Maggio, A. Choice of species and cultivars for protected cultivation. In Good Agricultural Practices for Greenhouse Vegetable Crops; FAO: Rome, Italy, 2013; pp. 97-108.

23. Muñoz-Sanz, J.V.; Zuriaga, E.; Cruz-García, F.; McClure, B.; Romero, C. Self-(In)compatibility Systems: Target Traits for CropProduction, Plant Breeding, and Biotechnology. Front. Plant Sci. 2000, 11, 195. [CrossRef]

24. Rodrigo, J.; Herrero, M. Evaluation of pollination as the cause of erratic fruit set in apricot 'Moniqui'. J. Hortic. Sci. 1996, 71, 801-805. [CrossRef]

25. Sanzol, J.; Herrero, M. Self-incompatibility and self-fruitfulness in pear cv. Agua de Aranjuez. J. Am. Soc. Hortic. Sci. 2007, 132, 166-171. [CrossRef]

26. Sánchez-Pérez, R.; Dicenta, F.; Martínez-Gómez, P. Identification of S-alleles in almond using multiplex-PCR. Euphytica 2004, 138, 263-269. [CrossRef]

27. Campoy, J.A.; Ruiz, D.; Egea, J. Dormancy in temperate fruit trees in a global warming context: A review. Sci. Hortic. 2011, 130, 357-372. [CrossRef]

28. Lee, K.L.; Cho, J.G.; Jeong, J.H.; Ryu, S.; Han, J.H.; Do, G.R. Effect of the Elevated Temperature on the Growth and Physiological Responses of Peach 'Mihong' (Prunus persica). Prot. Hortic. Plant Fact. 2020, 29, 373-380. (In Korean) [CrossRef]

29. Martínez-García, P.J.; Ortega, E.; Dicenta, F. Self-pollination does not affect fruit set or fruit characteristics in almond (Prunus dulcis). Plant Breed. 2011, 130, 367-371. [CrossRef]

30. Saez, A.; Aizen, M.A.; Medici, S.; Viel, M.; Villalobos, E.; Negri, P. Bees increase crop yield in an alleged pollinator-independent almond variety. Sci. Rep. 2020, 10, 3177. [CrossRef]

31. Erez, A.; Yablowitz, Z.; Korcinski, R.; Zilberstaine, M. Greenhouse growing of stone fruits: Effect of temperature on competing sinks. Acta Hortic. 2000, 513, 417-425. [CrossRef]

32. Wang, Z.Q.; Liu, S.E.; Niu, L.; Fan, W.; Liu, H.C. Study on tree training and pruning of nectarine in protected culture. J. Fruit Sci. 1999, 513, 417-425. (In Chinese)

33. Wang, H.; Wang, F.; Wang, G.; Majourhat, K. The responses of photosynthetic capacity, chlorophyll fluorescence and chlorophyll content of nectarine (Prunus persica var. Nectarina Maxim) to greenhouse and field grown conditions. Sci. Hortic. 2007, 112, 66-72. [CrossRef]

34. Sun, S.; Zhang, L.T.; Wang, J.X.; Wang, S.M.; Gao, H.J.; Gao, H.Y. Effects of low temperature and weak light on the functions of photosystem in Prunus armeniaca L. leaves in solar greenhouse. Ying Yong Sheng Tai Xue Bao 2008, 19, 512-516.

35. Galan, V. Greenhouse Cultivation of Tropical Fruits. Acta Hortic. 2002, 575, 725-735.

36. Allara, M.; Fredrix, M.; Bessy, C.; Prasterine, F. Product safety. In Good Agricultural Practices for Greenhouse Vegetable Crops; FAO: Rome, Italy, 2013; pp. 581-602.

37. Alonso, F.; Hueso, J.J.; Navarro, J.L.; Cuevas, L. Effects of plastic coverage on the earliness of the apirena Flame Seedless table grape cultivar. Actas Hortic. 2003, 39, 444-446. (In Spanish)

38. Wang, J.Z.; Zhang, A.N.; Fan, S.H. The present status and future of fruit protected cultivation in Shandong. Chin. Fruit 1999, 3, 46-48. (In Chinese)

39. Génard, M.; Bruchou, C. Multivariate analysis of within-tree factors accounting for the variation of peach fruit quality. Sci. Hortic. 1992, 52, 37-51. [CrossRef] 
40. Kong, Y.; Yao, Y.; Ma, C.; Li, B. Effect of canopy position on some fruit quality parameters of greenhouse-grown nectarine. Acta Hort. 2011, 893, 925-930. [CrossRef]

41. Kong, Y.; Chen, J.; Yao, Y.; Wang, Z.; Guo, J.; Lian, S.; Ma, C.; Li, B. The relationship between light transmittance and canopy structure parameters of nectarine trees in Chinese lean-to greenhouse. Acta Hortic. 2012, 927, 413-419. [CrossRef]

42. Marini, R.P.; Sowers, D.; Marini, M.C. Peach fruit quality is affected by shade during final swell of fruit growth. J. Am. Soc. Hortic. Sci. 1991, 116, 383-389. [CrossRef]

43. Mowa, E.; Kalili, M.; Akundabweni, L.; Percy, C. Impact of Organic Hydroponic Nutrient Solution on Tomato Fruit Quality. Int. Sci. Technol. J. Namib. 2018, 1, 62-77.

44. Wurm, L.; Urschler, W. Influence of plastic cover on fruit-quality and monilia laxa infestations with organically produced apricots. In Proceedings of the International Conference on Cultivation Technique and Phytopathological Problems in Organic FruitGrowing, Weinsberg, Germany, 18-20 February 2008; pp. 116-122.

45. Børve, J.; Meland, M.; Sekse, L.; Stensvand, A. Plastic covering to reduce sweet cherry fruit cracking affects fungal fruit decay. Acta Hortic. 2008, 795, 485-488. [CrossRef]

46. Wali, M.A. Integrated pest management and plant hygiene under protected cultivation. In Good Agricultural Practices for Greenhouse Vegetable Crops; FAO: Rome, Italy, 2013; pp. 399-426.

47. Lang, G.A. Growing sweet cherries under plastic covers and tunnels: Physiological aspects and practical considerations. Acta Hort. 2014, 1020, 303-312. [CrossRef]

48. Guvvali, T.; Nirmala, A.; Rao, B. Protected cultivation of fruit crops: A review. Int. J. Pure App. Biosci. 2017, 5, 1628-1634. [CrossRef]

49. Rubio, M.; García-Ibarra, A.; Martínez-Gómez, P.; Dicenta, F. Analysis of the main factors involved in the evaluation of Prunus resistance to Plum pox virus (Sharka) in control greenhouse conditions. Sci. Hortic. 2009, 123, 46-50. [CrossRef]

50. Rubio, M.; Gómez, E.M.; Martínez-Gómez, P.; Dicenta, F. Behaviour of apricot cultivars against Hop stunt viroid. J. Phytopathol. 2016, 164, 193-197. [CrossRef]

51. García-Ibarra, A.; Martínez-Gómez, P.; Dicenta, F.; Rubio, M. Evaluation of apricot (Prunus armeniaca L.) resistance to Apricot chlorotic leaf spot virus (ACLSV) in controlled greenhouse conditions. Eur. J. Plant Pathol. 2012, 133, 857-863. [CrossRef]

52. Martínez-Gómez, P.; Dicenta, F.; Egea, J. Breaking dormancy of GF305 peach and Real Fino apricot trees during the evaluation of resistance to sharka (Plum pox potyvirus). Agronomie 2000, 20, 885-892. [CrossRef]

53. Okie, W.R.; Reilly, C.C.; Nyczepir, A.P. Effect of Criconemella xenoplax and ClitovybeTabescenes on cold hardiness of greenhousegrown peach trees. Hortic. Sci. 1986, 21, 274-276.

54. Okie, W.R.; Nyczepir, A.P.; Reilly, C.C. Screening of peach and other Prunus species for resitance to ring nematode in greenhouse. J. Am. Soc. Hortic. Sci. 1987, 112, 67-70.

55. Culver, D.J.; Ramming, D.W.; McKenry, M.V. Procedures for field and greenhouse screening of Prunus genotypes for resistance and tolerance to root lesion nematode. J. Am. Soc. Hortic. Sci. 1989, 114, 30-35.

56. Erez, A.; Yablowitz, Z.; Korcinski, R. Greenhouse peach growing. Acta Hortic. 1998, 465, 593-600. [CrossRef]

57. Rodriguez, A.; Pérez-López, D.; Centeno, A.; Ruiz Ramos, M. Viability of temperate fruit tree varieties in Spain under climate change according to chilling accumulation. Agric. Syst. 2021, 186, 102961. [CrossRef]

58. Kubota, N.; Matthews, M.A.; Takahagi, T.; Kliewer, W.M. Budbreak with garlic preparations: Effects of garlic preparations and of calcium and hydrogen cyanamides on budbreak of grapevines grown in greenhouses. Am. J. Enol. Vit. 2000, 51, 409-414.

59. Gemma, H. Dormancy breaking in Japanese pears grown in a heated greenhouse. Acta Hortic. 1994, 395, 57-68. [CrossRef]

60. Erez, A. Means to compensate for insufficient chilling to improve bloom and leafing. Acta Hortic. 1995, 395, 81-95. [CrossRef]

61. Erez, A.; Yablowitz, Z.; Aronovitz, A.; Hadar, A. Dormancy Breaking Chemicals; Efficiency with Reduced Phytotoxicity. Acta Hortic. 2008, 772, 105-125. [CrossRef]

62. Prudencio, A.S.; Dicenta, F.; Martínez-Gómez, P. Monitoring dormancy transition in almond [Prunus dulcis (Miller) Webb] during cold and warm Mediterranean seasons through the analysis of a DAM (Dormancy-Associated MADS-Box) gene. Horticulturae 2018, 4, 41. [CrossRef]

63. Prudencio, A.S.; Díaz-Vivancos, P.; Dicenta, F.; Hernández, J.A.; Martínez-Gómez, P. Monitoring the transition from endodormancy to ecodormancy in almond through the analysis and expression of a specific Class III peroxidase gene. Tree Genet. Gen. 2019, 15, 44. [CrossRef]

64. Idso, S.B.; Kimball, B.A. Effects of atmospheric $\mathrm{CO}_{2}$ enrichment on photosynthesis, respiration, and growth of sour orange trees. Plant Physiol. 1992, 99, 341-343. [CrossRef] [PubMed]

65. Castilla, N. The greenhouse climate. In Greenhouse Technology and Management, 2nd ed.; Esteban, J.B., Ed.; CABI Publishing: Wallingford, UK, 2013; pp. 30-42.

66. Xi, W.; Zhang, Q.; Lu, X.; Wei, C.; Yu, S.; Zhou, Z. Improvement of flavor quality and consumer acceptance during postharvest ripening in greenhouse peaches by carbon dioxide enrichment. Food Chem. 2014, 164, 219-227. [CrossRef] [PubMed]

67. Selli, S.; Gubbuk, H.; Kafkas, E.; Gunes, E. Comparison of aroma compounds in Dwarf Cavendish banana (Musa spp. AAA) grown from open-field and protected cultivation area. Sci. Hortic. 2012, 141, 76-82. [CrossRef] 